\title{
Prediction of Major Wastewater Characteristics of Urban Wastewater Treatment Plant Using Fuzzy Composite Programing
}

\author{
A. K. Khambete ${ }^{1}$ - R. A. Christian ${ }^{1}$ - G. S. Anaokar ${ }^{1}$ (D)
}

Received: 14 March 2017 / Revised: 26 June 2017 / Accepted: 25 July 2017

(C) Springer Nature Singapore Pte Ltd. 2017

\begin{abstract}
Due to fluctuations in organic and hydraulic loading in a wastewater treatment plant, the application of fuzzy logic, using linguistic variables gave a better description of performance parameters. The study describes the strength of wastewater in terms of effluent wastewater index (EWWI). The EWWI was has been developed with fuzzy composite programming (FCP). Further dissolved oxygen (DO) of effluent wastewater is correlated with EWWI to predict different parameters such as, BOD, COD, SS, and TDS. Data for eight indicators (temperature, $\mathrm{pH}, \mathrm{SS}, \mathrm{TDS}, \mathrm{BOD}_{5}, \mathrm{COD}$, oil and grease, and chlorides), were collected. Weights were assigned on expert's perception. The index is equal to 0 if none of the eight pollutants are present in the effluent and to 1 when all eight parameters have corresponding value equal to, limits for discharge into surface water bodies defined by Gujarat pollution control board (GPCB). EWWI for irrigation and fishery was developed which is 0.5134 and 0.3205 , respectively. The index is a good tool for rapidly predicting the different parameters of effluent wastewater and monitoring the feasibility of wastewater in terms of its reuse. The proposed index could be of great help for managers and decision makers when monitoring the effluent samples and planning for reuse.
\end{abstract}

Keywords EWWI · Fuzzy composite programing ·

Prediction $\cdot$ Reuse

\section{G. S. Anaokar}

gsanaokar@gmail.com

1 Civil Engineering Department, Sardar Vallabhbhai National Institute of Technology, Surat, Gujrat 394 007, India

\section{Introduction}

Since many years, treating and disposing sewage is a big mission. At discharge point, it is very difficult to monitor whether all parameters of effluent are meeting the discharge norms or not. There is no full proof method for the same. Due to the scarcity of water, one must treat the wastewater, which can be reused rather than simply discharging the same in surface water bodies. The growing size of cities and the pollution caused by untreated sewage forced the legislation to set quality standards for treated sewage and funded sewage treatment facilities. In sewage treatment, the processes are designed and operated in order to copy the natural treatment processes so as to reduce pollution load up to a standards set by statutory bodies [11]. For this, it is required to evaluate the urban wastewater treatment plants with respect to the strength of treated wastewater, and its viability for correct reuse [4, 7].Since the last few years, more improvement is found in the wastewater treatment technologies, and that is the reason where effluents are found of better quality then earlier, [8]. By physical, chemical, and biological processes, the organic matters are digested and contaminates are removed in urban wastewater treatment plants. The treatment plant goal is to develop treated effluent which is very much safe for flora and fauna $[2,3,12]$. Once it is discharged, the same is assessed in laboratory for different parameters like BOD, COD, SS etc. to assure that all operational units are treating the wastewater up to discharge standards. In India, effluent standards have been set for disposal of wastewater, where different limits are given for the parameters for discharging the wastewater in different environmental sinks (environmental protection rules in India 1986). Instead of measuring number of parameters, it is necessary to understand the effluent wastewater in terms of its strength, which further helps in understanding its appropriate reuse [10, 12]. In 
this direction, wastewater polishing index was defined by [13], for the rapid quality assessment of reclaimed water. The analysis of large number of samples for physical, chemical, and microbiological parameters, which are described to regulate the discharge standards that can be avoided by evaluating wastewater index. In this study, effluent wastewater index (EWWI) of wastewater is evaluated with fuzzy application. Nezhad developed index by a weighted average of eight parameters (TSS, BOD5, COD, NH4, $\mathrm{PO}_{4}$, fecal coliform, TDS, and PH) which was obtained from Delphi method and fuzzy TOPSIS decision-making tools. Calculation of water quality rating curves (sub- indices) were based on giving a rating scores of $0,10,20,30,40,50,60,70,80,90$, and100 corresponding to the 5th, 10th, 20th, 30th, 40th, 50th, 60th, 70th, 80th, 90th, and 99 percentiles, respectively to each parameter observations. Then, the thresholds for different reuses and discharges are defined by using environmental limitations and developed EQI; [9]. The wastewater quality index of the influent wastewater in the existing treatment plant site at Puducherry was evaluated by Govindsassamy. The parameters considered for this study were $\mathrm{pH}$, TDS, TSS, BOD, COD, $\mathrm{N}$ as $\mathrm{NO}_{3}$, and $\mathrm{P}$ as $\mathrm{PO}_{4}$, which were used for the determination of WWQI and statistical analysis. Multiple linear regression (MLR) and artificial network analysis (ANN) models were also developed for WWQI and compared; [14]. Finally, the effluent quality of south wastewater treatment plant of Tehran for summer and autumn is evaluated using the developed EQI.

Fuzzy computation rules were used to express the absence of a sharp boundary between sets of information. Due to fluctuations in organic and hydraulic loading in a wastewater treatment plant, the application of fuzzy logic, using linguistic variables gave a better description of performance parameters. The study describes the strength of wastewater in terms of EWWI, which is later correlated with dissolved oxygen and predicted values of EWWI, and was used to predict the important parameters of effluent wastewater. In any water body for assessing quality, DO is considered as important parameter. DO can be measured instantaneously by DO meter, and while studying the huge collected data; it has come to notice/ observe that as the index is increasing DO is reducing and vice versa. Therefore, the graph was plotted and it showed very good interrelation.

\section{Methodology}

The index was developed using modified fuzzy composite programming technique. As per the notification of state pollution control board, parameters were selected. The composite procedure involves a step-by-step regrouping of a set of various basic indicators to form a single indicator [1, 6]. Figure 1 shows the hierarchy composite structure of the basic indicators selected for determining EWWI. The set of basic indicators were grouped in to smaller sub sets of second level indicators and at third level the EWWI is found after primary and secondary treatments.

The normalization process is performed by using best and worst first level indicator values. Evidently, in a number of cases the minimum values represent the best situation. Bardossy and Duckstein (1992) noted that the best and worst values may be crisp (un-fuzzy) or fuzzy in nature. These values were assumed to be crisp for the present application [5].

\section{Selection of Basic Criterion/Indicators}

The different effluent parameters are selected as criteria and they are then used as the input variables to evaluate each alternative. In order to show how preference weights are obtained, the procedure, called analytic hierarchy process (AHP), can be used. Each of first level indicators such as temperature, TDS, and SS (Fig. 1) is compared in pairwise manner using Saaty's weights. The weights were assigned by researcher. By this procedure, $3 \times 3$ matrix A can be constructed as follows. The matrix $A$ for trial 1 for temperature, TDS, and SS is as shown by matrix, A1 is presented as viii. Three trials were run with different weights to determine differences in the final decision index for treated wastewater which shows the different perceptions of the importance of each criterion (three different weights for three individual trials).

$$
\mathrm{A} 1=\begin{gathered}
\text { Temp. } \\
\text { TDS } \\
\mathrm{SS}
\end{gathered}\left[\begin{array}{ccc}
1 & 1 / 3 & 1 / 6 \\
3 & 1 & 1 / 3 \\
6 & 3 & 1
\end{array}\right] \quad \mathrm{W}=\left[\begin{array}{l}
0.09 \\
0.25 \\
0.66
\end{array}\right]
$$

Weight, $W$, was obtained by solving matrix $A$; using eigenvalue Eq. (i). This will result in to a unit eigenvector $W$ corresponding to $\Phi_{\max }$ giving the preference weights. Thus, weighting coefficients, $W$ for temperature, TDS, and SS are $0.09,0.25$, and 0.66 , respectively. The consistency of the judgments made by the decision makers is reflected by consistency ratio always less than 0.1 .

It is essential to have a method to measure the degree of consistency among the pairwise judgments provided by the decision maker. If the degree is acceptable then the decision process continues or else the decision maker should reconsider and possibly revise the pairwise judgments before proceeding with the analysis. A measure of consistency used by the AHP that can be computed is known as the consistency ratio (CR). This ratio designed so that values of the ratio exceeding 0.1 are indicative of inconsistent judgments indicating that the decision maker would probably want to revise the original values in the pairwise comparison matrix. The consistency index 
Fig. 1 Hierarchy for the EWWI by FCP

\section{CRITERION}

Lerel $1 \mathrm{Si} h(\mathrm{X})$
CHARACTE RISTICS

Lerel $2 \mathrm{~L} j, \mathrm{~h}(\mathrm{X})$
E WWTI

Lesel 3 L k,h $(X)$

\section{EFFLUENT WASTEWATER}

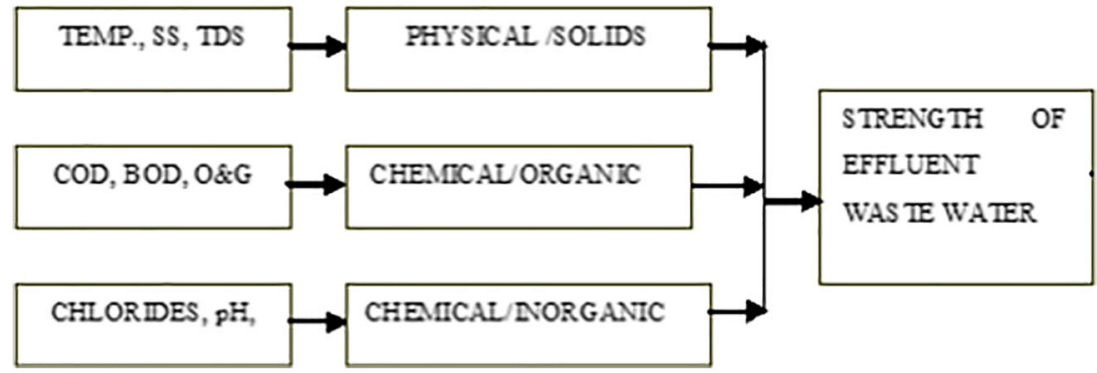

which is defined as $\mathrm{CI}=\lambda_{\max }-n / n-1$, where $n$ is the number of items being compared and $\lambda_{\max }=$ approximation of the maximum eigenvalue and the consistency ration (CR) which is $\mathrm{CR}=\mathrm{CI} / \mathrm{RI}$, where, $\mathrm{RI}$ is the random index, and CI is the consistency index of a randomly generated pairwise comparison matrix. CR is calculated. The consistency index CR for above matrix A1 is 0.015 , which is less than 0.1 , and indicates consistency in judgment for allotting weights in pairwise comparison. Similarly, weights for second trial and third trial are calculated for level 1 and level 2 which are shown in Table 4.

\section{Construction of Membership Function}

The second step in FCP is the normalization of the basic indicators to convert non-commensurate indicators into unit less entities. This is necessary because all basic indicators have different units and are difficult to compare in their respective units. In order to evaluate the fuzzy number of different indicators, the most likely and largest likely interval for different parameters was selected. This graphically presented as trapezoid in Fig. 2. "Experts" perception of best and worst values of indicators was selected. In order to evaluate the overall efficiency of WWTP with elements of uncertainty, let $Z_{\mathrm{i}}(x)$ be a fuzzy number of the $i$ th basic criteria, and lets its membership function $\mu\left[Z_{\mathrm{i}}(x)\right]$ be a trapezoid, Fig. 2, where $x$ denotes an element of the discrete set of parameters alternative being analyzed. If the trapezoid is reduced to a vertical line, it represents a so-called crisp number. A level-cut concept (Dong and Shah, 1987) is used to define the interval of each basic indicator at various levels of "confidence."

\section{Normalizing the Basic Criterion}

The membership function for each of the basic criteria can be constructed as shown in Fig. 2, where $Z_{\mathrm{i}, \mathrm{h}}(x)$ is an interval value of the $i$ th basic criteria at the confidence level (membership degree) h, [i.e., $a \leq Z_{\mathrm{i}, \mathrm{h}}(x) \leq \mathrm{b}$ ]. The best and worst value for the basic criterion is determined by expert's perceptions.

Using the best value of $Z_{\mathrm{i}}\left(\mathrm{BESZ}_{\mathrm{i}}\right)$ and the worst value of $Z_{\mathrm{i}}$ $\left(\mathrm{WORZ}_{\mathrm{i}}\right.$ ) for the $i$ th basic indicators, the actual value $Z_{\mathrm{i}, \mathrm{h}}(x)$ is transformed into an $i$ th normalized basic criterion value.

The actual value $Z_{\mathrm{i}, \mathrm{h}}(x)$ is transformed into an index value $S_{\mathrm{i}, \mathrm{h}}(x)$ denoted by Fig. 3 . Since the actual value $Z_{\mathrm{i}, \mathrm{h}}(x)$ is an interval with lower bound "a" and upper bound "b," see Fig. 3 the index value $S_{\mathrm{i}, \mathrm{h}}(x)$ resulting from $Z_{i, \mathrm{~h}}(x)$ is also an interval, see Fig. 3. In the model for evaluating the MPAI the "a" is minimum value, i.e., $\mathrm{BESZ}_{\mathrm{i}}$ in data and " $\mathrm{b}$ " is maximum value, i.e., $\mathrm{WORZ}_{\mathrm{i}}$ in observed data. For evaluating $S_{\mathrm{i}, \mathrm{h}}(x)$ for indicators, at first level, any one of the Eqs. (i) or (ii) is used.
Fig. 2 Fuzzy estimate of ith basic indicator

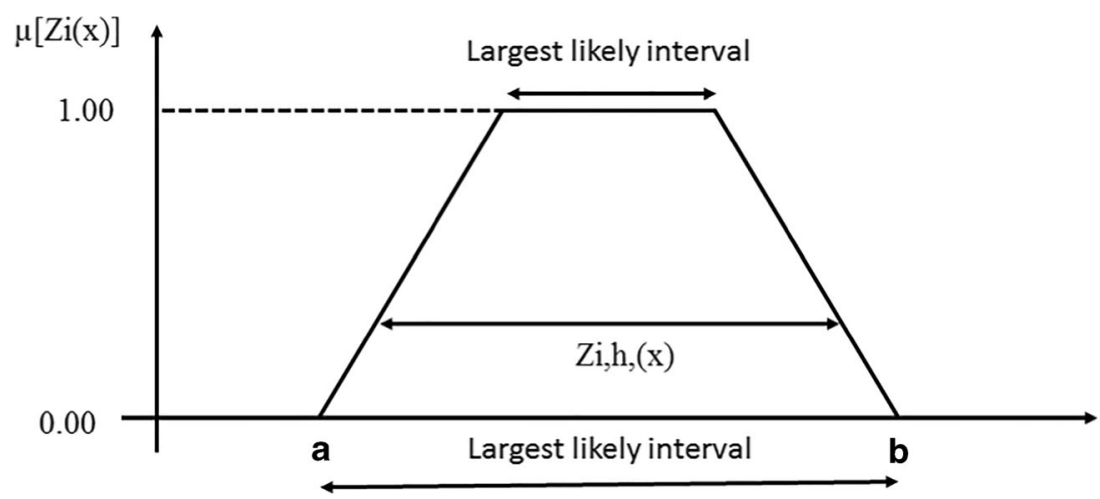


Fig. 3 Transferring actual value $Z_{\mathrm{i}, \mathrm{h}}(\mathrm{x})$, into index $S_{\mathrm{i}, \mathrm{h}}(x)$
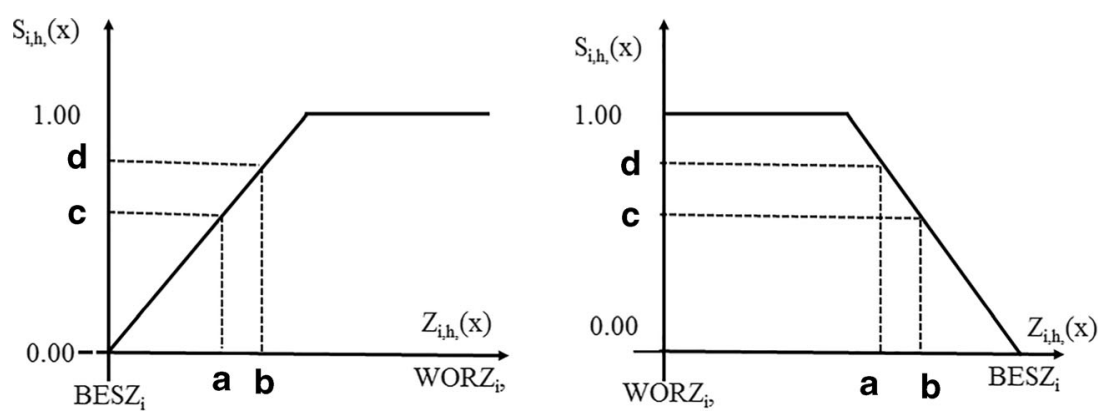

In this model $\mathrm{BESZ}_{\mathrm{i}} \leq \mathrm{WORZ}_{\mathrm{i}}$, and $\mathrm{BESZ}_{\mathrm{i}}$ is a minimum value, $\left(\mathrm{Z}_{\mathrm{i}^{-}}\right)$of all the parameters and $\mathrm{WORZ}_{\mathrm{i}}$,

If $\mathrm{WORZ}_{\mathrm{i}}>\mathrm{BESZ}_{\mathrm{i}}$, then

$$
\begin{aligned}
& \mathrm{S}_{\mathrm{i}, \mathrm{h}}(\mathrm{x})= \\
& {\left[\begin{array}{cc}
1, & \mathrm{Z}_{\mathrm{i}, \mathrm{h}}(\mathrm{x}) \geq W O R Z_{\mathrm{i}} \\
{\left[\mathrm{Z}_{\mathrm{i}, \mathrm{h}}(\mathrm{x})-B E S Z_{\mathrm{i}}\right] /\left(W O R Z_{\mathrm{i}}-B E S Z_{\mathrm{i}}\right),} & B E S Z_{\mathrm{i}}<\mathrm{Z}_{\mathrm{i}, \mathrm{h}}(\mathrm{x})<W O R Z_{\mathrm{i}} \\
0, & \mathrm{Z}_{\mathrm{i}, \mathrm{h}}(\mathrm{x}) \leq B E S Z_{\mathrm{i}}
\end{array}\right]}
\end{aligned}
$$$$
\mathrm{S}_{\mathrm{i}, \mathrm{h}}(\mathrm{x})=
$$$$
\ln \left[\begin{array}{cc}
1, & \mathrm{Z}_{\mathrm{i}, \mathrm{h}}(\mathrm{x}) \geq W O R Z_{\mathrm{i}} \\
{\left[\mathrm{Z}_{\mathrm{i}, \mathrm{h}}(\mathrm{x})-B E S Z_{\mathrm{i}}\right] /\left(W O R Z_{\mathrm{i}}-B E S Z_{\mathrm{i}}\right),} & W O R Z_{\mathrm{i}}<\mathrm{Z}_{\mathrm{i}, \mathrm{h}}(\mathrm{x})<B E S Z_{\mathrm{i}} \\
0, & \mathrm{Z}_{\mathrm{i}, \mathrm{h}}(\mathrm{x}) \leq B E S Z_{\mathrm{i}}
\end{array}\right]
$$

Maximum permissible value, $\left(\mathrm{Z}_{\mathrm{i}}\right)$ that is the limits is prescribed by GPCB for all the parameters for discharging treated wastewater in surface water body. The Eq. (iv) can be presented as below.

$$
S_{\mathrm{i}}=\frac{Z_{\mathrm{i}}-\mathrm{Z}_{\mathrm{i}-}}{\mathrm{Z}_{\mathrm{i}+}-\mathrm{Z}_{\mathrm{i}-}}
$$

Using the index values of basic indicators, index values, $L_{\mathrm{j}}$, $\mathrm{h}(x)$, of second level composite indicators can be defined by the Eq. (iv).

$$
\mathbf{L}_{\mathbf{j}, \mathbf{h}}(\mathbf{x})=\left\{\sum_{i=1}^{n_{j}} w_{i j}\left[\mathbf{S}_{\mathbf{i}, \mathbf{h}, \mathbf{j}}(x)\right]^{p_{j}}\right\}^{1 / p_{j}}
$$

Where,

$n_{\mathrm{j}} \quad$ the number of elements in the second level group $j$, $S_{\mathrm{i}, \mathrm{h}} \quad$ the index value for the ith indicator in the second j(x) level group $j$ of basic indicators, $w_{\mathrm{ij}} \quad$ the weight reflecting the importance of each basic indicator in the second level group $j$,

$p_{\mathrm{j}} \quad$ the balancing factor for the second level group $j$.

The processes available for determining the weights and balancing factor are written in detail in the section followed.

Further, index values $L_{\mathrm{k}, \mathrm{h}}(x)$ of third level composite indicator can calculated by using the index value for second level indicators, or

$\mathbf{L}_{\mathbf{k}, \mathbf{h}}(\mathbf{x})=\left\{\sum_{j=1}^{n_{k}} w_{j k}\left[\mathbf{L}_{\mathbf{j}, \mathbf{h}, \mathbf{k}}(x)\right]^{p_{k}}\right\}^{1 / p_{k}}$

Where,

$n_{\mathrm{k}} \quad$ the number of elements in the third level group $k$,

$L_{\mathrm{j}, \mathrm{h} \mathrm{k}} \quad$ the index value for the $j$ th indicator in the third level (x) group $\mathrm{k}$ of basic indicators,

$W_{\mathrm{jk}} \quad$ the weight reflecting the importance of each basic indicator in the third level group $k$,

$p_{\mathrm{k}} \quad$ the balancing factor for the third level group $k$.

The final step is the composition between the two-index value of the fourth level indicator such as MPAI of raw wastewater and MPAI of treated wastewater. For example, the index value $L_{1}(x)$, for the final composite indicator can be calculate by

Equation $\mathrm{ID}=\mathrm{t}=\mathrm{b}=$

$\mathbf{L}_{\mathbf{l}, \mathbf{h}}(\mathbf{x})=\left\{\boldsymbol{w}_{\mathbf{1}}\left[\mathbf{L}_{1, \mathbf{h}}(\boldsymbol{x})\right]^{p}+\boldsymbol{w}_{\mathbf{2}}\left[\boldsymbol{L}_{2, \mathbf{h}}(\boldsymbol{x})\right]^{p}\right\}^{\frac{1}{p}}$

Where,

$L_{1, \mathrm{~h}}(x) \quad$ the index value for the first indicator (MPAI for raw) in the final group,
Table 1 Maximum, minimum, and average values of effluent wastewater of STP

\begin{tabular}{llllllllll}
\hline Wastewater & Strength & Temp. & TDS & SS & BOD & COD & O\&G & Cl & pH \\
\hline Effluent & Max & 33.80 & 792.00 & 40.00 & 23.00 & 128.00 & 0.80 & 360.00 & 8.05 \\
& Min & 24.50 & 634.00 & 6.00 & 5.00 & 32.00 & 0.10 & 280.00 & 7.49 \\
& Average & 28.90 & 732.07 & 22.14 & 12.28 & 67.81 & 0.41 & 317.93 & 7.70 \\
\hline
\end{tabular}


Table $2 \mathrm{Si}, j(x)$; normalized values at second level hierarchy

\begin{tabular}{|c|c|c|c|c|c|c|c|c|c|}
\hline \multicolumn{2}{|c|}{ Wastewater } & \multirow{2}{*}{$\begin{array}{c}\text { Temp. } \\
0.8450\end{array}$} & \multirow{2}{*}{$\begin{array}{l}\text { TDS } \\
0.3771\end{array}$} & \multirow{2}{*}{$\begin{array}{l}\text { SS } \\
0.4000\end{array}$} & \multirow{2}{*}{$\frac{\text { BOD }}{0.7667}$} & \multirow{2}{*}{$\frac{\text { COD }}{1.2800}$} & \multirow{2}{*}{$\frac{O \& G}{0.0800}$} & \multirow{2}{*}{$\begin{array}{l}\mathrm{Cl} \\
0.6000\end{array}$} & \multirow{2}{*}{$\frac{\mathrm{pH}}{0.5866}$} \\
\hline Treated & Max & & & & & & & & \\
\hline & Min & 0.6125 & 0.3019 & 0.0600 & 0.1667 & 0.3200 & 0.0100 & 0.4667 & 0.2733 \\
\hline & Average & 0.7225 & 0.3486 & 0.2214 & 0.4093 & 0.6781 & 0.0410 & 0.5299 & 0.3933 \\
\hline
\end{tabular}

$L_{2, \mathrm{~h}}$ (x) the index value for the second indicator (MPAI for treated) in the final group,

$w_{1}$ and the weights indicating the relative importance $w_{2} \quad$ between the two indicators in the final group and $p \quad$ balancing factor for the final group.

In this model, the MPAI for raw water and MPAI for treated wastewater are allotted equal weight 1 and balancing factor is considered 1. Due to the treatment processes, there is reduction in the MPAI for treated wastewater therefore $L_{2, \mathrm{~h}}(x)$ is subtracted, from $L_{1, \mathrm{~h}}(x)$ and the reduction in the strength of wastewater evaluated.

\section{Determination of Weights}

In Equations (v), (vi), and (vii), weights and balancing factors are given to each indicator and group. This represents a double weighing scheme. Weighting coefficients assessed are, to reflect the relative importance of each of the indicators. To calculate the weighting coefficient for each of the indicators, the procedure developed by (Saaty 1988) is applied. The procedure, called the analytic hierarchy process (AHP), can be used to obtain the relative weight of each of the indicators in a group based on a paired comparison of each of the indicators. The weights are established based on the degree of relative importance of each criterion, as determined by decision makers. Since we used a hierarchical structure to obtain the composite of the criterion in this study, weights determined are by the pairwise comparison proposed by Saaty. Using the pairwise comparison, weights can be calculated such that the relative weight of each criterion in a group is illustrated.

Table 3 Best and worst indicator values for criterions

\begin{tabular}{llll}
\hline Sr. no. & Criterions & Best values & Worst values \\
\hline 1. & Temperature 0C & 0 & 40 \\
2. & TDS mg/L & 0 & 2100 \\
3. & SS mg/L & 0 & 100 \\
4. & BOD mg/L & 0 & 30 \\
5. & COD mg/L & 0 & 100 \\
6. & O\&G mg/L & 0 & 10 \\
7. & Chlorides mg/L & 0 & 600 \\
8. & pH & 7.0 & $\leq 6.5$ and $\geq 8.5$ \\
\hline
\end{tabular}

Subsequently, decision makers have to construct matrix "A," that is, the pairwise comparison matrix of $m$ parameters constructed based on Saaty's scaling ratio of the order $(\mathrm{m} \times \mathrm{m})$, as follows:

Construct matrix $A=\left[a_{\mathrm{i}} \mathrm{j}\right],\left(a_{\mathrm{ij}} \mid \mathrm{i}=1,2 \ldots \ldots m ; \mathrm{j}=1,2 \ldots . \mathrm{m}\right)$

Where $a_{\mathrm{ij}}=\mathrm{w}_{\mathrm{j}} / \mathrm{w}_{\mathrm{i}}$ for all $i$ and $j$.

Matrix $A$ generally has the properties of reciprocality and consistency, i.e., mathematically $a_{\mathrm{ij}}=1 / \mathrm{a}_{\mathrm{ji}}$, and $\mathrm{a}_{\mathrm{ik}}=1 / \mathrm{a}_{\mathrm{ki}}$ for any $i, j$, and $k$.

According to matrix theory, if the comparison matrix $A$ has the property of consistency, the system of equations has a trivial solution. Matrix $A$ is, however, a judgment matrix and it may not be possible to determine accurately the elements of $A$ to satisfy the property of consistency. Therefore, a linear, homogeneous Eq. (vii) estimates weight factor.

Equation $\mathrm{ID}=\mathrm{t}=\mathrm{b}=$ Equation $\mathrm{ID}=\mathrm{t}=\mathrm{b}=$

$\mathrm{A}^{\prime} \times \mathrm{W}^{\prime}=\Phi_{\max } \times \mathrm{W}^{\prime}$

Where, $A^{\prime}=$ estimate of $A ; W^{\prime}=$ corresponding priority vector; and $\Phi_{\max }=$ largest eigenvalue for matrix $A$. Eq. (vii) yields the weight scalar corresponding to largest eigenvalue.

Table 4 Weights used at second and third hierarchy levels for three trials

\begin{tabular}{llllll}
\hline Levels & Criteria & \multicolumn{2}{l}{ Weights $(W i, j)$} & \multirow{2}{*}{$P$} \\
\cline { 3 - 5 } & & Trial - 1 & Trial - 2 & Trial - 3 & Trial - 1, 2, 3 \\
\hline Levels 2 & Temperature & 0.09 & 0.08 & 0.07 & 1 \\
& TDS & 0.25 & 0.27 & 0.30 & 1 \\
& SS & 0.66 & 0.65 & 0.63 & 1 \\
& BOD & 0.40 & 0.47 & 0.43 & 1 \\
& COB & 0.40 & 0.38 & 0.43 & 1 \\
& O\&G & 0.20 & 0.15 & 0.14 & 1 \\
& Cl & 0.17 & 0.20 & 0.15 & 1 \\
& pH & 0.83 & 0.80 & 0.85 & 1 \\
Level 3 & Characteristics & Trial - 1 & Trial - 2 & Trial - 3 & Trial - 1, 2, 3 \\
& Solids & 0.29 & 0.333 & 0.33 & 1 \\
& Organic & 0.35 & 0.333 & 0.41 & 1 \\
& Inorganic & 0.36 & 0.333 & 0.26 & 1 \\
\hline
\end{tabular}


Table $5 \mathrm{Lj}, h, k(x)$, second-hierarchy level for three trials

\begin{tabular}{|c|c|c|c|c|c|c|c|c|c|}
\hline \multirow[t]{2}{*}{ No. of trials $\mathrm{Lj}, h, k(x)$} & \multicolumn{3}{|l|}{ Solids } & \multicolumn{3}{|l|}{ Organic } & \multicolumn{3}{|l|}{ Inorganic } \\
\hline & Trial - 1 & Trial - 2 & Trial - 3 & Trial - 1 & Trial - 2 & Trial - 3 & Trial - 1 & Trial - 2 & Trial - 3 \\
\hline Max & 0.4343 & 0.5331 & 0.5263 & 0.7604 & 0.8033 & 0.8173 & 0.5946 & 0.5960 & 0.5937 \\
\hline Min & 0.2223 & 0.2193 & 0.2164 & 0.2840 & 0.3058 & 0.3053 & 0.2850 & 0.2870 & 0.2836 \\
\hline Average & 0.3784 & 0.3753 & 0.3722 & 0.6117 & 0.6361 & 0.6575 & 0.4125 & 0.4159 & 0.4102 \\
\hline
\end{tabular}

Moreover, the unit eigenvector $\left(W^{\prime}\right)$ corresponding to $\Phi_{\max }$ yields then preference weights for the criteria compared (Saaty 1990).

\section{Determination of Balancing Factors}

The balancing factor $p(p \geq 1)$ are assigned to groups of the indicators to reflect the importance of the maximal deviation, where the maximal deviation means the maximum difference between an indicator value and the best value for that indicator. The larger the value of the balancing factor, the greater the concern with respect to the maximal deviation. When $p=1$, all deviation is equally weighted. When $p=2$, each division receives its importance in proportion to its magnitude. As the value $p$ becomes larger and larger, the deviation has more and more importance.

\section{Results and Discussion}

As case studies, field data with maximum, minimum, and average values from STP located at Surat are considered. Table 1 below presents the maximum, minimum, and average values for the period of 4 months of treated wastewater.

The criterions (data of parameters) were normalized using Eq. 1-2, and are shown in Table 2 below. With the help of the Eq. 3, the $\mathrm{Si}, j(x)$; normalized fuzzy value of first level indicators are determined as shown in Table 2.

The worst (maximum possible values) and best (minimum possible values) were determined from statutory norms set by governing authorities; Table 3 present the most likely (best) and maximum likely (worst) values for effluent wastewater criterion. These criterions are described by GPCB for discharging treated wastewater in surface water sources.

\section{Determination of weights and balancing factors at second and third level}

For sensitivity analysis, weights for all three trials were determined by the researcher. Weights (wij) represent the relative importance between indicators in given group. Greater the importance of an indicator, greater is the weight assigned to it. In order to show how the preference weights are obtained for each of the first level indicators such as temperature, TDS, and SS are grouped in characteristics as physical/solids, in second level indicator labeled as Lj, $h(x)$ (Table 4).

The balancing factor used for the study reflects the importance of maximal deviations of the indicators. This maximal deviation is the maximum difference between an indicator values and the best value for the indicator. In this research, the balancing factor values were determined by researcher. The balancing factor used is 1 for the first, second, and third trials. The $\mathrm{Lj}, h(x)$, for second level is determined, with the help of Eq. 5. The Si $h(x)$ and $\mathrm{Wi}, j$ values would be the input and are as per the data given in Tables 2 and 5 , respectively. The $\mathrm{Lj}, h, k(x)$, values are presented in Table 5 below.

Further, the index values, $\mathrm{Lk}, h,(x)$, of third level composite indicators can be calculated by using the index values for second level composite indicators, which is as shown in Eq. 5. The Lk, $h(x)$ of third level composite indicators for three trials is shown in Table 6 below. This is MPAI for raw and treated wastewater.

\section{Predicting EWWI and Parameters}

It was observed that the parameters are correlated with DO. Graphical plots were developed between DO v/s EWWI from which predicted EWWI was obtained. Plots of EWWI v/s BOD, COD, and SS parameters were also developed. These plots were used to predict EWWI, BOD, COD, and SS strengths.

\section{Prediction of EWWI and Different Parameters for Treated Wastewater}

Here, the data of measured DO for treated wastewater and EWWI developed for treated wastewater is considered. The graph is plotted between DO v/s EWWI which is presented in Fig. 4 below.

Table 6 EWWI for effluent wastewater L1, $h(x)$

\begin{tabular}{llll}
\hline No. of trials & Trial - & Trial - 2 & Trial - 3 \\
\hline Max & 0.6062 & 0.6443 & 0.6631 \\
Min & 0.2665 & 0.2707 & 0.2703 \\
Average & 0.4723 & 0.4759 & 0.4991 \\
\hline
\end{tabular}




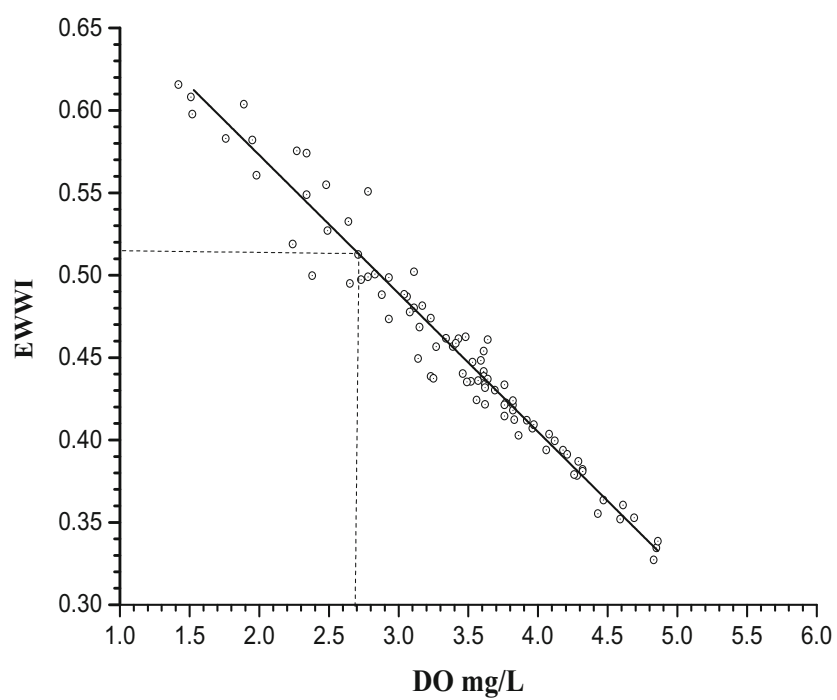

Fig. 4 Plot of measured DO V/s EWWI

Here, dependent variable $Y$ is EWWI observed and independent variable $X$ is observed DO in $\mathrm{mg} / \mathrm{L}$ of treated wastewater. Where, adj. $R^{2}$ is 0.9588 . The graph shows that, when DO is higher the value of EWWI is lower and with lower value of DO, the value of EWWI is higher. For example: from Fig. 4 if DO is $2.7 \mathrm{mg} / \mathrm{L}$ than EWWI estimated is 0.51 and DO is $4.5 \mathrm{mg} / \mathrm{L}$, EWWI estimated is 0.36 .

\section{Predicting BOD}

EWWI was predicted from Fig. 4 above. Now the plot of predicted EWWI v/s BOD was plotted as shown in Fig. 5 below. Where, value of adj. $R^{2}=0.8392$. The lines are prediction. And from these lines different parameters were predicted and predicted data was compared statistically with actual or observed data to show the frequency occurrence. In same line for every STPs EWWI can be derived and with the help of

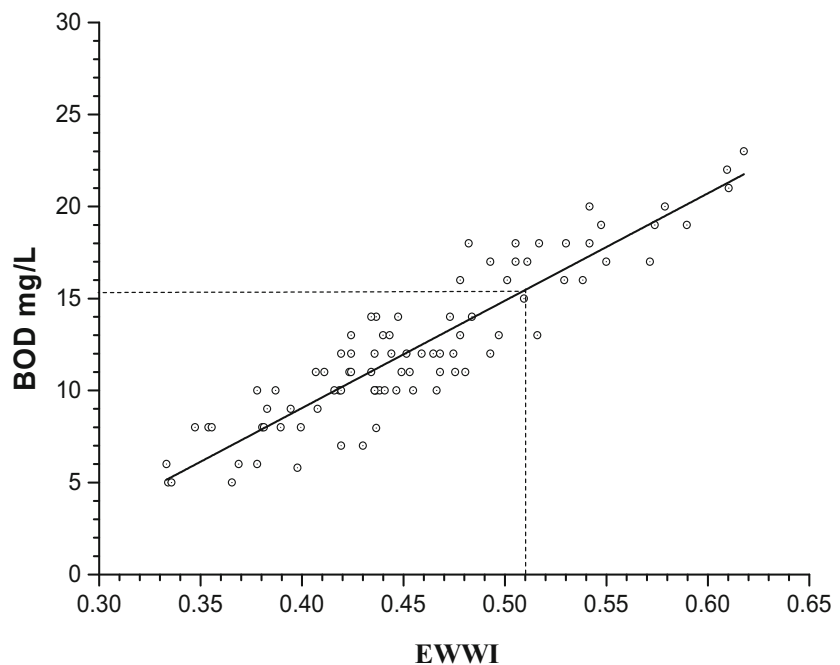

Fig. 5 Plot obtained for observed BOD v/s EWWI

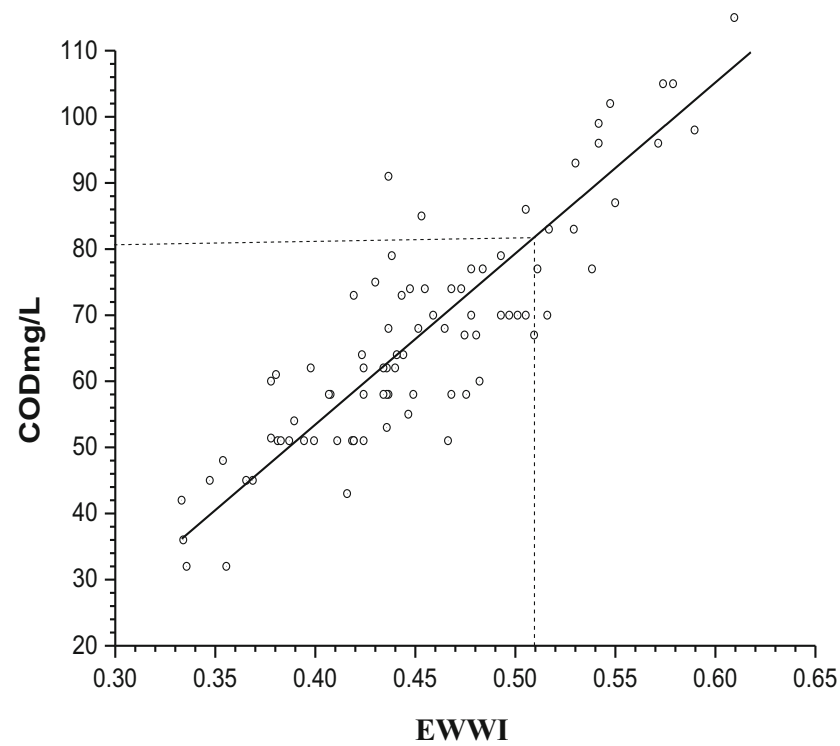

Fig. 6 Plot for Observed COD v/s EWWI

relative graphs parameters can be predicted. Which otherwise take minimum $3 \mathrm{~h}$ to 3 days to evaluate.

In Fig. 5, the dependent variable $Y$ is observed BOD and independent variable $X$ is EWWI predicted.

\section{Predicting COD}

The graph was plotted between predicted EWWI v/s COD as shown in Fig. 6 below. The adj. $R^{2}$ is 0.7917 . Here, dependent variable $Y$ is COD observed and independent variable $X$ is predicted EWWI from Fig. 6.

\section{Predicting SS}

The EWWI predicted and the measured SS was plotted graphically as shown in Fig. 7 Where adj. $R^{2}=0.4958$. Here,

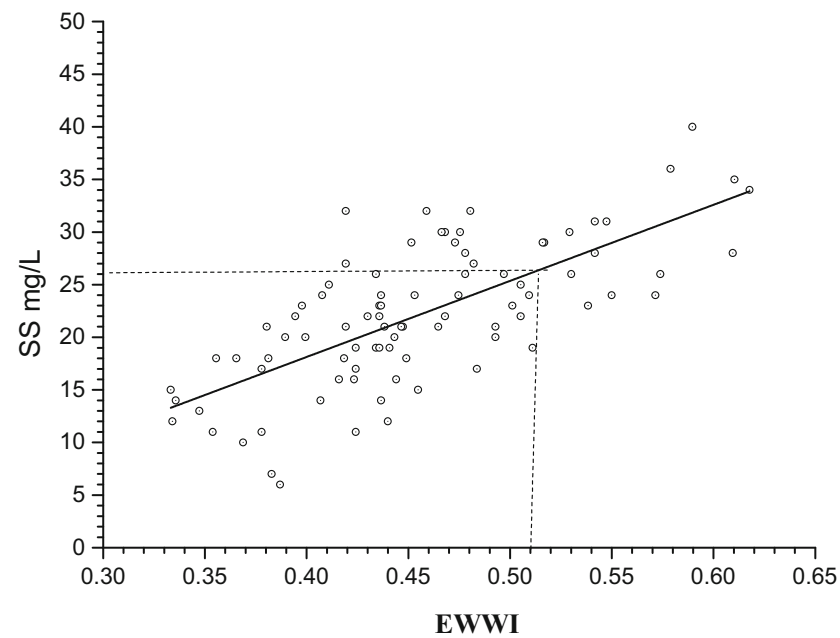

Fig. 7 Plot obtained for EWWI predicted v/s measured SS 
Table 7 Frequency distribution of different parameters

\begin{tabular}{|c|c|c|c|c|c|c|}
\hline Observed DO range & 4.86 & $4.85-4.17$ & $4.16-3.48$ & $3.47-2.80$ & $2.79-2.11$ & $2.10-1.42$ \\
\hline MPAI range & $0.33-0.39$ & $0.40-0.45$ & $0.46-0.50$ & $0.51-0.55$ & $0.56-0.60$ & $0.61-0.67$ \\
\hline Frequency for observed data & 1 & 11 & 32 & 25 & 9 & 8 \\
\hline Frequency for predicted data & 1 & 14 & 30 & 22 & 13 & 7 \\
\hline BODo range & $5.00-8.59$ & $8.60-12.19$ & $12.20-15.79$ & $15.80-19.39$ & $19.40-22.99$ & $23.00-26.60$ \\
\hline BODP range & $5.15-8.46$ & $8.47-11.78$ & $11.79-15.10$ & $15.11-18.42$ & $18.43-21.74$ & $21.75-25.06$ \\
\hline Frequency for observed data & 3 & 14 & 36 & 12 & 17 & 5 \\
\hline Frequency for predicted data & 1 & 14 & 30 & 22 & 13 & 7 \\
\hline CODo range & $32.29-48.59$ & $48.60-65.19$ & $65.20-81.79$ & $81.80-98.39$ & $98.40-114.99$ & $115.00-131.60$ \\
\hline CODp range & $36.38-50.89$ & $50.90-65.61$ & $65.62-80.33$ & $80.34-95.05$ & $95.06-109.77$ & $109.78-124.50$ \\
\hline Frequency for observed data & 2 & 7 & 35 & 26 & 10 & 7 \\
\hline Frequency for predicted data & 1 & 14 & 30 & 22 & 13 & 7 \\
\hline SSo range & $6.00-12.79$ & $12.80-19.59$ & $19.60-26.39$ & $26.40-33.19$ & $33.20-39.99$ & $40.00-46.80$ \\
\hline SSp range & $13.30-17.40$ & $17.41-21.52$ & $21.53-25.63$ & $25.64-29.75$ & $29.76-33.86$ & $33.87-33.00$ \\
\hline Frequency for observed data & 1 & 7 & 22 & 35 & 18 & 4 \\
\hline Frequency for pre-data range & 1 & 14 & 30 & 22 & 13 & 7 \\
\hline
\end{tabular}

All parameters are measured and predicted in $\mathrm{mg} / \mathrm{L}$

dependent variable $Y$ is observed SS and independent variable $X$ is predicted EWWI from Fig. 7.

The frequency distribution for observed and predicted data of $\mathrm{DO}, \mathrm{BOD}, \mathrm{COD}$, and $\mathrm{SS}$ is presented data is shown in Table 7 below. This helps in predicting parameters of treated wastewater against measured DO of wastewater.

\section{Application of EWWI for Wastewater Reuses}

Table 8 shows reuse of treated wastewater from the MPAI evaluated against different effluent standards. It shows that if the treatment plant runs with an efficiency of $48.85 \%$, the treated water can be reused for irrigation.

Moreover, if the efficiency of the treatment plant is 57.09 , $78.26,90.00$, and $95.89 \%$, the treated wastewater can be reused for irrigation, fishery, mineral water, and reverse osmosis (RO) treated water, respectively. It can be observed that, with the given set of weights, the EWWI for water to be discharged at GPCB Standards is 0.82 (it is nost 1 because $\mathrm{pH}$ selected is 7.6), for irrigation standards it is 0.35 . If it is treated up to standards for fishery, EWWI is 0.18 and for standard of mineral water the EWWI is 0.08 . With EWWI

Table 8 Efficiency of WWTP with different effluent standards

\begin{tabular}{|c|c|c|c|c|c|c|c|c|}
\hline \multirow[t]{2}{*}{ Sr. No. } & \multirow[t]{2}{*}{ Parameters } & \multirow[t]{2}{*}{ Weights } & \multicolumn{6}{|c|}{ Effluent standards for different reuse } \\
\hline & & & GPCB & Irrigation & Fishery & $\begin{array}{l}\text { Mineral } \\
\text { water }\end{array}$ & R.O. & $\begin{array}{l}\text { Distilled } \\
\text { water }\end{array}$ \\
\hline 1. & Temp. & \multirow{8}{*}{$\begin{array}{l}\text { Used as shown in Table } 4 \\
\text { for trial } 1 \text { for criterion } \\
\text { and characteristics (3) }\end{array}$} & 40 & 25 & 25 & 25 & 25 & 25 \\
\hline 2. & TDS & & 2100 & 1000 & 500 & 250 & 125 & 3 \\
\hline 3. & SS & & 100 & 50 & 25 & 10 & 5 & 0 \\
\hline 4. & BOD & & 30 & 15 & 7 & 3 & 0 & 0 \\
\hline 5. & COD & & 100 & 50 & 25 & 12 & 0 & 0 \\
\hline 6. & $O \& G$ & & 10 & 5 & 2 & 0 & 0 & 0 \\
\hline 7. & Chlorides & & 600 & 300 & 150 & 70 & 35 & 0 \\
\hline 8. & $\mathrm{pH}$ & & 7.6 & 7 & 7 & 7 & 7 & 7 \\
\hline 9. & EWWI & - & $0.82^{\mathrm{a}}$ & 0.35 & 0.18 & 0.08 & 0.03 & 0.016 \\
\hline 10. & $\begin{array}{l}\text { Reduction with GPCB } \\
\text { standard }\end{array}$ & 0.47 & 0.64 & 0.73 & 0.79 & 0.81 & & \\
\hline 11. & $\begin{array}{l}\text { Efficiency of WWTP in \% for } \\
\text { reuses in \% }\end{array}$ & 57.09 & 78.26 & 90.00 & 95.89 & 98.00 & & \\
\hline
\end{tabular}

${ }^{\mathrm{a}}$ It would have been 1 if $\mathrm{pH}$ is 6.5 or 8.5 
of 0.03 and 0.016 , the wastewater can be reused as water produced from RO or as distilled water respectively. The criterion is vague and the first time an attempt is made to evaluate EWWI by fuzzy approach. For sensitivity analysis, the EWWI is to evaluate with three trials by AHP. At present, for any treated wastewater, different parameters are measured. If critical parameters like BOD and COD are exciding their discharge norm, then these facts can be revealed after 3 days or $2 \mathrm{~h}$ depending on the type of parameter. During that period, huge quantity of effluent is getting discharged in the river bodies. This method gives instant results of EWWI, BOD, and COD with an error of $10 \%$ by just measuring DO with a DO meter.

\section{Conclusion}

In this study, a new index EWWI has been developed. This index evaluates the wastewater quality index for treated wastewater. The index developed is a scalar value by analyst's judgment, expert human knowledge, experience, and available literature. Quantification of this index is subjected to uncertainties for many reasons including difficulties in defining input and output parameters, and consequences of severity and mathematics of combining them. From the analysis of the present study, following conclusions have been drawn. Application of fuzzy approach to the standard of pollution control is found more appropriate compared to the current crisp approach. The EWWI index developed with FCP was plotted with DO concentrations. Lower DO concentrations give higher EWWI and higher DO concentrations in sample gives lower EWWI. Higher index presents wastewater with greater strength and requires further treatment as per its reuse. EWWI less than 0.35 indicates that treated water can be used for irrigation purpose. The strength of effluent wastewater in terms of EWWI by FCP methodology with three trials, for maximum values of parameters for selected data is 0.6062 , 0.6443 , and 0.6631 , respectively. For minimum values of parameters for selected data is $0.2665,0.2707$, and 0.2703 , respectively. And for average values of parameters for selected data is recorded as $0.4723,0.4759$, and 0.4991 , respectively.

\section{References}

1. Almedeij J et al (2013) Water level forecasting through fuzzy logic and artificial neural network approaches. European Journal of Advances in Engineering and Technology 2(23):10-22 Available at: http://www.academicjournals.org/journal/SRE/article-abstract/ D574C2F34176

2. Arslan G, Aydin Ö (2009) A new software development for fuzzy multicriteria decision-making. Technol Econ Dev Econ 15(2):197212 Available at: http://www.scopus.com/inward/record.url?eid=2s2.0-70949085582\&partnerID=tZOtx3y1

3. Boller M (1997) Small wastewater treatment plants - a challenge to wastewater engineers. Water Sci Technol 35(6):1-12. Available at: https://doi.org/10.1016/S0273-1223(97)00089-9

4. Colmenarejo MF et al (2006) Evaluation of municipal wastewater treatment plants with different technologies at las Rozas, Madrid (Spain). J Environ Manag 81(4):399-404

5. Coppola E a, Duckstein L, Davis D (2002) Fuzzy rule-based methodology for estimating monthly groundwater recharge in a temperate watershed. J Hydrol Eng 7(4):326-335

6. Dodgson JS et al. 2009 Multi-criteria analysis : a manual Available at: http://eprints.lse.ac.uk/12761/1/Multi-criteria_Analysis.pdf

7. Jamrah AI 1999 Assessment of characteristics and biological treatment technologies of Jordanian wastewater. Bioprocess Engineering

8. Mesdaghinnia, Hamedian R 2011 Mesdaghinia.pdf., pp.30-32

9. Nezhad MF, Mehrdadi N, Torabian A (2015) Definition of a new domestic effluent quality index using TOPSIS decision making tool. Can J Pure Appl Sci 9(2):3467-3472

10. Nuhoglu A, Keskinler B, Yildiz E 2005 Mathematical modelling of the activated sludge process - The Erzincan case. Process Biochemistry

11. Kumar R, Liza Britta Pinto P, Somashekar R (2010) Assessment of the efficiency of sewage treatment plants : a comparative study between Nagasandra and Kathmandu University. Journal of Science, Engineering And Technology 6:115-125

12. Semiromi B et al (2011) Water quality index development using fuzzy logic: a case study of the Karoon River of Iran. Afr J Biotechnol 10(50):10125-10133 Available at: http://www. academicjournals.org/ajb/full text/2011/5Sep/babaei Semiromi et al.htm

13. Verlicchi $\mathrm{P}$ et al. 2010 Wastewater polishing index : A tool for a rapid quality assessment of reclaimed wastewater Wastewater polishing index : a tool for a rapid quality assessment of reclaimed wastewater

14. Vijayan G, Saravanane R, Sundararajan T 2016 Wastewater Quality Index - A Tool for Categorization of the Wastewater and Its Influence on the Performance of Sequencing Batch Reactor., 7(1), n69-88 